\title{
The Effectiveness of Cystography-Measured Bladder Neck Elevation at Predicting the Return of Continence After Robot-Assisted Radical Prostatectomy
}

\author{
Jung Sik Huh, Young-Joo Kim, Sung Dae Kim, Kyung Kgi Park \\ Department of Urology, School of Medicine, Jeju National University, Jeju, Korea
}

Purpose: To analyze the clinical parameters correlated with early recovery of urinary continence after radical prostatectomy, with a focus on urethral mobility during pelvic contraction at catheter removal.

Methods: We prospectively analyzed 67 patients who underwent prostatectomy for prostate cancer at Jeju National University Hospital from January 2015 to June 2018. At the time of catheter removal, a cystography was performed in 67 men (median age, 65 years; range, 55-76 years) who had undergone robot-assisted laparoscopic prostatectomy. The vertical length of bladder neck movement between relaxing and contracting the pelvic muscles was measured. The correlation between the rate of continence recovery and the length of urethral movement was also assessed. All participants were divided into 2 groups according to the length of bladder neck elevation. Group 1 had $\geq 0.6 \mathrm{~cm}$ of elevation, while group 2 demonstrated $<0.6 \mathrm{~cm}$ of elevation.

Results: A reverse correlation existed between the length of urethral movement and the recovery rate of urinary continence $(r=-0.488$, $\mathrm{P}<0.001$ ). The optimal cutoff value for length of urethral movement was found to be $0.6 \mathrm{~cm}$ among patients (area under the curve, 0.703). A statistically significant difference was observed between group 1 (length $\geq 0.6 \mathrm{~cm}$ ) and group $2(<0.6 \mathrm{~cm})$ $(\mathrm{P}<0.05)$. Multivariate regression analysis showed that urethral movement predicted the postoperative urinary incontinence. Conclusions: The extent of bladder neck elevation after robot-assisted laparoscopic prostatectomy, which can be easily evaluated using cystography, may be a good predictor of the recovery of urinary continence.

Keywords: Prostate cancer; Cystography; Urinary incontinence; Prostatectomy

- Grant/Fund Support: This work was supported by a research grant from Jeju National University Hospital in 2017.

- Research Ethics: The Institutional Review Board (IRB) provided approval for this study to be conducted at Jeju National University Hospital (IRB

No. 2018-08-006-001). Written informed consent by the patients was waived by the IRB due to a chart review.

- Conflict of Interest: No potential conflict of interest relevant to this article was reported.

\section{INTRODUCTION}

Many patients who undergo radical prostatectomy experience stress urinary incontinence after the procedure. However, the rate of incontinence decreases with time. Until about 12 months postoperatively, urinary incontinence was controlled in more than $95 \%$ of patients [1]. Nevertheless, urinary incontinence is a major complication, and most patients complain of it during that time, even if they understand that it is a temporary condition. Several preoperative urodynamic parameters have been introduced as predictors of early continence recovery [2].

Previous studies have revealed the mechanism of postprosta-
Corresponding author: Kyung Kgi Park (D) https://orcid.org/0000-0001-9807-1461 Department of Urology, Jeju National University Hospital, School of Medicine, Jeju National University, 15 Aran 13-gil, Jeju 63231, Korea

E-mail: urology.park@gmail.com / Tel: +82-64-717-1760 / Fax: +82-64-717-1521

Submitted: April 15, 2019 / Accepted after revision: July 27, 2019
This is an Open Access article distributed under the terms of the Creative Commons Attribution Non-Commercial License (http://creativecommons.org/licenses/by-nc/4.0/) which permits unrestricted non-commercial use, distribution, and reproduction in any medium, provided the original work is properly cited. 
tectomy incontinence to be the impairment of various muscles and nerves surrounding the urethral sphincter, rectum, and bladder neck. These injuries often delay patients' recovery from postoperative incontinence [1]. Therefore, many researchers reported the various static imaging parameters to represent the postoperative status of periurethral muscles [3-5]. However, we believed that this status should be evaluated with dynamic diagnostic methods. Because if patients are able to contract their rhabdosphincter, it might be considered an indicator of intact rhabdosphincter and periurethral muscles. Therefore, it could be hypothesized that the contractile urethral length may be a good tool to use to identify whether the muscle and nerve structure surrounding the urethra has been preserved. We evaluated the correlation between the calculated contractile urethral length using cystography and the duration of postoperative incontinence in patients who had undergone a radical prostatectomy.

\section{MATERIALS AND METHODS}

The participants in this study were 67 men who underwent radical prostatectomy from January 2015 to June 2018 (Table 1). The median age of the patients was 67 years (standard deviation, \pm 4.8 ). We used cystography to measure the amount of urethral movement between relaxing and contracting the pelvic muscles when the urethral catheter was removed postoperatively.

The patients were classified into 2 groups according to the length of urethral movement. Based on an optimal cutoff level, 29 patients with urethral movement of $0.6 \mathrm{~cm}$ or more were placed in group 1, and 38 patients who demonstrated movement of less than $0.6 \mathrm{~cm}$ were categorized in group 2 .

The mean number of postoperative days that passed before the urethral catheter was removed was $7.0 \pm 1.9$ days. All patients underwent follow-up for a minimum of 6 months, and the longest follow-up period was 3 years. The Institutional Review Board provided approval for this study to be conducted at Jeju National University Hospital.

\section{Protocol for Radiologic Procedures}

We instilled 10\% diluted contrast media into the bladder under gravity until the patient reported a sensation of fullness. Sequencing films were taken every 10 seconds during the proce-

Table 1. Participant characteristics $(n=67)$

\begin{tabular}{|c|c|c|c|c|}
\hline \multirow{2}{*}{ Characteristic } & \multirow{2}{*}{ Total } & \multicolumn{2}{|c|}{ Degree of BN elevation } & \multirow{2}{*}{ P-value } \\
\hline & & Group 1 & Group 2 & \\
\hline No. of patients (\%) & 67 & $29(43.2)$ & $38(56.7)$ & \\
\hline Age (yr) & $67 \pm 4.8$ & $62 \pm 5.3$ & $69 \pm 4.4$ & 0.12 \\
\hline Prostate volume (mL) & $45 \pm 16.3$ & $46 \pm 17.9$ & $44 \pm 14.9$ & 0.78 \\
\hline Initial total IPSS & $12 \pm 7.4$ & $9 \pm 2.1$ & $14 \pm 7.9$ & 0.13 \\
\hline Initial QoL & $4 \pm 1.6$ & $3 \pm 1.2$ & $4 \pm 1.7$ & 0.21 \\
\hline Initial Qmax & $14.9 \pm 7.1$ & $15.3 \pm 6.7$ & $14.7 \pm 5.6$ & 0.67 \\
\hline $\begin{array}{l}\text { Pathologic stage } \\
\leq \text { T2N0M0 } \\
\geq \text { T3N0M0 }\end{array}$ & $\begin{array}{l}35(52.2) \\
32(57.8)\end{array}$ & $\begin{array}{l}14(48.2) \\
15(51.8)\end{array}$ & $\begin{array}{l}21(55.2) \\
18(44.7)\end{array}$ & 0.98 \\
\hline $\begin{array}{l}\text { Intraoperative parameters } \\
\text { BN opening } \\
\text { Narrow } \\
\text { Moderate } \\
\text { Wide } \\
\text { NBV saving }\end{array}$ & $\begin{array}{c}4(5.9) \\
51(76.1) \\
12(17.9) \\
39(58.2)\end{array}$ & $\begin{array}{r}4(12.5) \\
18(62.5) \\
7(24.1) \\
15(51.7)\end{array}$ & $\begin{array}{r}0(0) \\
33(86.8) \\
5(13.1) \\
24(62.5)\end{array}$ & 0.25 \\
\hline Length of urethral movement $(\mathrm{cm})$ & $0.5 \pm 0.9$ & $0.9 \pm 0.6$ & $0.2 \pm 0.1$ & $<0.001$ \\
\hline Time to recovery (mo), mean \pm SD & $1.7 \pm 0.7$ & $0.5 \pm 0.1$ & $2.4 \pm 1.2$ & $<0.001$ \\
\hline
\end{tabular}

Values are presented as median \pm standard deviation (SD) or number (\%) unless otherwise indicated.

BN, bladder neck; IPSS, International Prostate Symptom Score; QoL, quality of life; Qmax, maximum flow rate; NBV, neurovascular bundle. All patients were divided into 2 groups according to the length of bladder neck elevation. Group 1 demonstrated $0.6 \mathrm{~cm}$ or more of elevation, while group 2 had $<0.6 \mathrm{~cm}$ of elevation. 


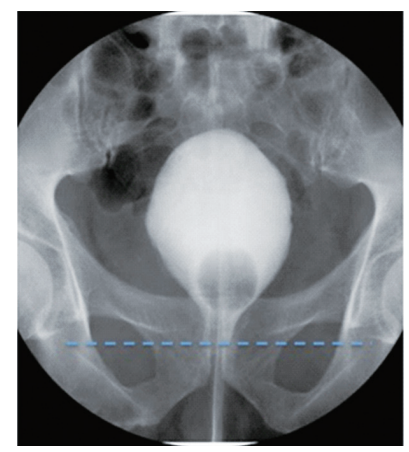

Relax

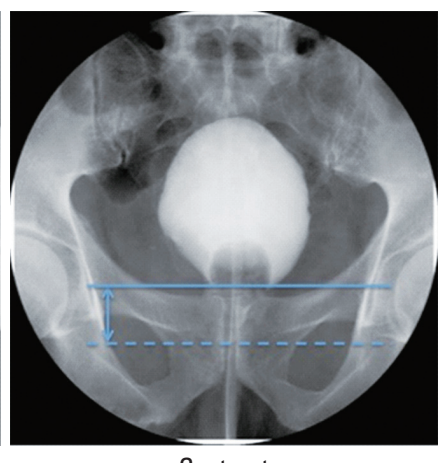

Contract
Fig. 1. Cystography after radical prostatectomy. The arrow defines the vertical length of urethral movement; dotted line, relaxing status; solid line, contracting status.

dure to identify any urethrovesical anastomosis (UVA) leakage. After the patients reported a full bladder, an anterior posterior view and both oblique views of the bladder were obtained. Next, the patients were instructed to contract the pelvic muscle, such as when performing a Kegel exercise, to identify movement of the bladder neck, which was recorded by radiography. After draining the contrast media from the bladder, a postdrainage view of the bladder was also obtained. During the cystography, the cystography-measured bladder neck ascendable vertical length was defined as the vertical length of the contrastfilled bladder's apex between the time the pelvic muscles were relaxed and the time they were contracted (Fig. 1). If the patient did not effectively contract the pelvic muscles in the first trial, a second trial was carried out after coaching the patient on how to properly contract the pelvic muscles. Each measurement was taken as 3 and 4 times and the highest value has been indicated by a final urethral movement length.

Urinary continence status was assessed when patients visited the office every week until postoperative day 14 and then was evaluated every month thereafter until postoperative month 3 . From that point forward, patients were asked every 3 months about urinary continence. The recovery of urinary continence was defined as a pad-free condition for daily living without anxiety about urinary leakage.

\section{Statistical Analysis}

The 2 groups were compared to determine their baseline parameters using a 1-way analysis of variance. A univariate analysis of time to restore continence was performed using the logrank test. To ascertain the optimal cutoff value to anticipate urinary continence recovery, a receiver-operating characteristic

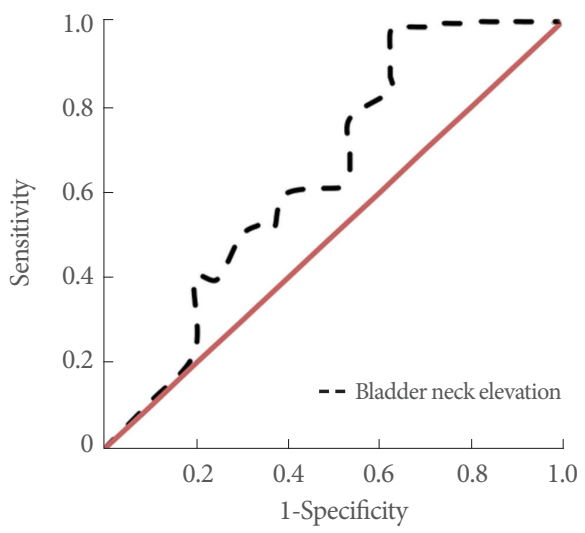

Fig. 2. Receiver-operating characteristic curves created from vertical length of urethral movement and the postoperative recovery of urinary continence to distinguish subjects reporting incontinence from those who did not.

curve (ROC) was used. To identify any associations between bladder neck elevation and the period of urinary incontinence, a Spearman correlation test was performed. Statistical analysis was carried out using Prism ver. 5.1D (GraphPad Software Inc., San Diego, CA, USA). Perioperative factor (may influenced the postoperative incontinence) were taken multivariate analysis with $\mathrm{R}$ logistic regression model (R Foundation for statistical computing, Vienna, Austria).

\section{RESULTS}

The median length of urethral movement during cystography was $0.5 \mathrm{~cm}$ (range, $0-1.5 \mathrm{~cm}$ ). There were no significant differences between groups 1 and 2, except bladder neck elevation and incontinence recovery rate (Table 1). Age, tumor staging, degree of bladder neck opening, and percent of nerve sparing were not revealed their clinically significance in analysis. We used an ROC analysis to determine the optimal cutoff value of urethral movement for predicting the postoperative recovery of urinary continence. A cutoff value of $0.6 \mathrm{~cm}$ gave the best accuracy in our ROC analysis. The area under the ROC curve, sensitivity, and specificity values were $0.703,0.583$, and 0.863 , respectively (Fig. 2).

The median lengths of urethral movement were $0.9 \mathrm{~cm}$ in group 1 and $0.2 \mathrm{~cm}$ in group 2. Four of the 38 patients in group 2 showed no urethral movement. When we compared the time to recovery of urinary incontinence in both groups, the mean time to recovery in group 1 was 0.5 months, and in group 2 were 2.4 months, respectively. Group 1 was significantly shorter 
Table 2. Results of univariate and multivariate logistic regression analysis

\begin{tabular}{|c|c|c|c|c|c|c|}
\hline \multirow{2}{*}{ Risk factor } & \multicolumn{3}{|c|}{ Univariate } & \multicolumn{3}{|c|}{ Multivariate } \\
\hline & OR & $95 \% \mathrm{CI}$ & P-value & OR & $95 \% \mathrm{CI}$ & P-value \\
\hline Age (yr) & 1.09 & $1.00-1.19$ & 0.042 & 1.1 & $0.98-1.23$ & 0.108 \\
\hline $\operatorname{BMI}\left(\mathrm{kg} / \mathrm{m}^{2}\right)$ & 1.05 & $0.87-1.27$ & 0.606 & - & - & - \\
\hline PSA (ng/mL) & 1.01 & $0.96-1.06$ & 0.775 & - & - & - \\
\hline Operative time (min) & 1.01 & $0.99-1.02$ & 0.176 & - & - & \\
\hline Nerve sparing (yes/no) & 0.64 & $0.14-2.91$ & 0.546 & - & - & - \\
\hline BN opening (narrow vs. wide) & 0.86 & $0.56-1.27$ & 0.078 & - & - & - \\
\hline Prostate volume (mL) & 1.03 & $0.99-3.45$ & 0.107 & - & - & - \\
\hline Pathologic T stage ( > T3 vs. $\leq \mathrm{T} 2$ ) & 2.72 & $0.64-10.4$ & 0.214 & - & - & - \\
\hline Urethral M ( $>0.6 \mathrm{~cm}$ vs. $\leq 0.6 \mathrm{~cm})$ & 0.32 & $0.20-0.57$ & $<0.001$ & 0.36 & $0.20-0.67$ & 0.002 \\
\hline
\end{tabular}

OR, odds ratio; CI, confidence interval; PSA, prostate-specific antigen; BN, bladder neck; Urethral M, urethral movement calculated by cystography.

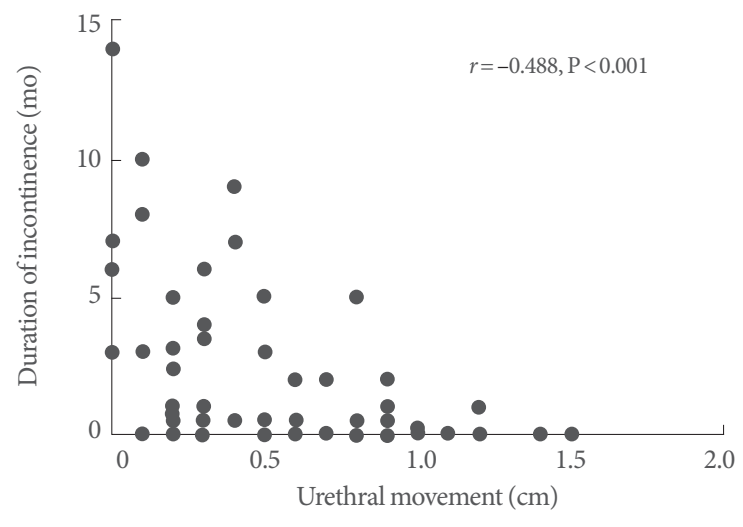

Fig. 3. The distribution of the duration of postoperative urinary incontinence according to the measured degree of bladder neck elevation on postoperative day 7 using cystography.

than in group 2 (Table 1).

Perioperative risk factors may influence the postoperative incontinence were analysis with multiple regression. In univariate logistic regression analysis, 2 variables reached statistically significant and were included in the multivariate logistic regression model: age (odds ratio [OR], 1.09; 95\% confidence interval [CI], 1.00-1.19; $\mathrm{P}=0.042)$, urethral movement (OR, 0.32; 95\% CI, 0.20-0.57; $\mathrm{P} \leq 0.001)$. Multivariate analysis revealed that urethral movement (OR, 0.36; 95\% CI, 0.20-0.67; $\mathrm{P}=0.002$ ) was independent predictor of postoperative UI after prostatectomy (Table 2).

Spearman correlation analysis revealed an inverse correlation between the length of urethral movement and the urinary incontinence volume rate on day 7 after urethral catheter removal $(r=-0.488, \mathrm{P} \leq 0.001)$ (Fig. 3). There was also a significant dif-

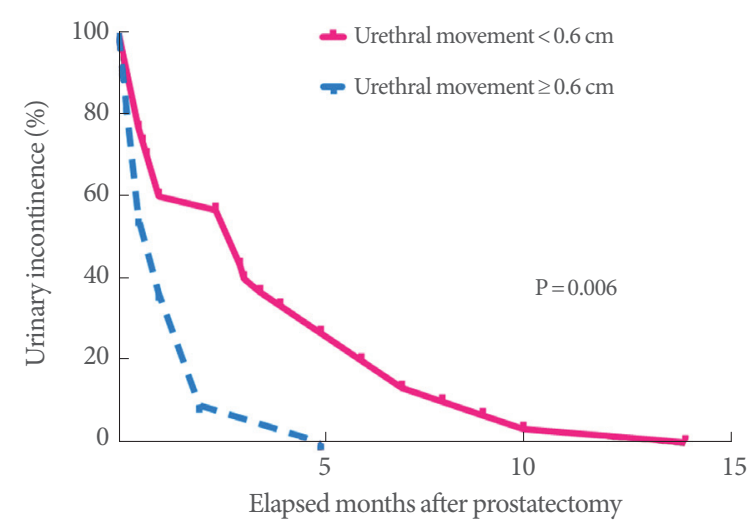

Fig. 4. Postoperative incontinence recovery percent according to the degree of bladder neck elevation.

ference in continence recovery between the 2 groups until 10 months postoperatively (Fig. 4).

\section{DISCUSSION}

Many prostate cancer patients suffer from postoperative incontinence for a brief period of time because the prostatectomy itself can create temporary or permanent functional and structural dysfunctions. Hammerer and Huland [2] reviewed the urodynamic evaluations of changes in urinary control in patients following radical retropubic prostatectomy. They found that the mean functional urethral length, maximal urethral closing pressure, and bladder capacity decreased in these patients. Therefore, they argued that these dysfunctions of the urethra can have a significant influence on continence after 
radical prostatectomy. As a result, urologic surgeons are eager to reduce the chances of postoperative incontinence by saving the periurethral structure. Hamada et al. [6] reported that a maximal urethral length preservation technique could allow for the early return of continence. They also argued that securing a long urethra was more effective in restoring postoperative continence than posterior urethral reconstruction and anterior bladder suspension. Lee et al. [7] reported the good result of postoperative continence based on their continuous urethrovesical anastomosis technique. Their patients with continuously suturing had a less UVA leakage and postoperative incontinence rather than interrupted suturing. The return of urinary continence after surgery is influenced by multiple factors, including patient selection, technical nuances, and definitions [1].

To evaluate these various factors together, we set out to develop a simple method to immediately identify preserved periurethral muscles to confirm the possibility of the recovery of postoperative urinary continence.

Twiss et al. [8] proposed a new index to use to predict the return of urinary continence 3 months after radical prostatectomy. Patients showed incontinence rates of $96 \%, 85 \%$, and $68 \%$ at 1,2 , and 3 months postoperatively, respectively, according to their continence index categories. It is important to provide prognostic information for each man as soon as possible to relieve his anxiety; the continence index assesses continence status at the time of catheter removal. However, we believe that this method was not simple and did not include any information about the postoperative function of the periurethral muscle.

Skarecky et al. [9] reported that they did not find reliable preoperative factors to predict restoring previous levels of urinary continence in their study. However, in a subsequent study, they found the number of pads used daily at 4-7 days after catheter removal was an accurate predictor. The median time to continence for men using 1 pad was 35 days, 2 pads was 42 days, and 3 or more pads was 73 days. This method was simple, but it did not offer an immediate predictor of continence recovery following catheter removal. Several researches [3-5] reported their static cystographic findings after prostatectomy. As they have been reported, many static cystographic findings could estimate the postoperative urinary continence. In addition to that, some researchers the similar results were reported using preoperative magnetic resonance imaging $[10,11]$. However, we believed that dynamic evaluation of cystography is needed.

Usually, before urethral catheter removal, we evaluate the UVA using urethrocystography. At that time, we intervened with a new, simple method, which was a maneuver similar to a Kegel exercise. It requires no additional effort and can identify whether patients can effectively contract their pelvic muscles. Based on the results of this study, patients who demonstrated a good contraction of the pelvic muscles could reduce the length of the postoperative urinary incontinence period. The degree of contraction can be easily identified using cystography. Therefore, we believe this method is feasible to use.

The anatomical location and fiber characteristics of the periurethral levator ani muscle suggest that these fibers actively assist in urethral closure, particularly during events that cause elevation of intra-abdominal pressure [12]. According to the present study, the periurethral muscle can support urethral closing. Therefore, we believe that it could be evaluated during pelvic muscle contraction by radiographic assessment to measure the degree of elevation of the bladder neck and pelvic muscle contraction and preservation of the periurethral muscle. However, Kenton and Brubaker [13] reported that the ability to contract the levator ani does not appear to be related to the ability to activate motor unit action potentials in the urethral sphincter in women. This finding means that the functions of the levator ani are independent from maintaining the closing function of the urethral sphincter. Therefore, we believe that to identify the exact muscle complex involved with urinary incontinence, further study is needed. However, the ability to elevate the bladder neck can be used to estimate the return of urinary continence.

In this study, we objectively measured the length of urethral movement using cystography. Based on an optimal cutoff value of $0.6 \mathrm{~cm}$, the group with more elevation showed a faster recovery from postoperative incontinence than the other patients. In clinical practice, these results may help to estimate the period required to restore urinary continence and determine the prognosis of postoperative incontinence in applicable patients. There were a few limitations to this study. We calculated the duration of incontinence using information provided by the patients when they visited the clinic for follow-up. This method could make the result inaccurate by recall errors. Therefore, it was possible that the exact duration of incontinence may have been somewhat incorrect.

In conclusion, this study suggests that the amount of bladder neck ascending movement on cystography was significantly associated with early recovery from postprostatectomy incontinence. This method of assessment is easy to carry out and is also useful for predicting the course of incontinence. 


\section{AUTHOR CONTRIBUTION STATEMENT}

- Full access to all the data in the study and takes responsibility for the integrity of the data and the accuracy of the data analysis: KKP

- Study concept and design: KKP

- Acquisition of data: KKP

- Analysis and interpretation of data: $Y J K, S D K$

- Drafting of the manuscript: JSH, KKP

- Critical revision of the manuscript for important intellectual content: JSH, YJK, SDK, KKP

- Statistical analysis: KKP

- Obtained funding: KKP

- Administrative, technical, or material support: KKP

- Study supervision: KKP

\section{REFERENCES}

1. Loughlin KR, Prasad MM. Post-prostatectomy urinary incontinence: a confluence of 3 factors. J Urol 2010;183:871-7.

2. Hammerer P, Huland H. Urodynamic evaluation of changes in urinary control after radical retropubic prostatectomy. J Urol 1997; 157:233-6.

3. Sugi M, Kinoshita H, Yoshida T, Taniguchi H, Mishima T, Yoshida $\mathrm{K}$, et al. The narrow vesicourethral angle measured on postoperative cystography can predict urinary incontinence after robot-assisted laparoscopic radical prostatectomy. Scand J Urol 2018; 52:151-6.

4. Fukui S, Kagebayashi Y, Iemura Y, Matsumura Y, Samma S. Postoperative cystogram findings predict recovery of urinary continence after robot-assisted laparoscopic radical prostatectomy. Low Urin Tract Symptoms 2019;11:143-50.
5. Jeong SJ, Yi J, Chung MS, Kim DS, Lee WK, Park H, et al. Early recovery of urinary continence after radical prostatectomy: correlation with vesico-urethral anastomosis location in the pelvic cavity measured by postoperative cystography. Int J Urol 2011;18:444-51.

6. Hamada A, Razdan S, Etafy MH, Fagin R, Razdan S. Early return of continence in patients undergoing robot-assisted laparoscopic prostatectomy using modified maximal urethral length preservation technique. J Endourol 2014;28:930-8.

7. Lee SW, Han DH, Lee KS, Jeon SS. Effect of Continuous Urethrovesical anastomosis technique in incontinence after radical retropubic prostatectomy, 1:1 matching study. Int Neurourol J 2015;19: 113-9.

8. Twiss C, Martin S, Shore R, Lepor H. A continence index predicts the early return of urinary continence after radical retropubic prostatectomy. J Urol 2000;164:1241-7.

9. Skarecky D, Morales B, Chang A, Ahlering T. Simple method to predict return of continence after robot-assisted radical prostatectomy. J Endourol 2011;25:1451-5.

10. Sadahira T, Mitsui Y, Araki M, Maruyama Y, Wada K, Edamura K, et al. Pelvic magnetic resonance imaging parameters predict urinary incontinence after robot-assisted radical prostatectomy. Low Urin Tract Symptoms 2019;11:122-6.

11. Neumann PB, O'Callaghan M. The role of preoperative puborectal muscle function assessed by transperineal ultrasound in urinary continence outcomes at 3, 6, and 12 months after robotic-assisted radical prostatectomy. Int Neurourol J 2018;22:114-22.

12. Gosling JA, Dixon JS, Critchley HO, Thompson SA. A comparative study of the human external sphincter and periurethral levator ani muscles. Br J Urol 1981;53:35-41.

13. Kenton K, Brubaker L. Relationship between levator ani contraction and motor unit activation in the urethral sphincter. Am J Obstet Gynecol 2002;187:403-6. 